\title{
Polymorphisms on SSC15q21-q26 Containing QTL for reproduction in Swine and its association with litter size
}

\author{
Hongli $\mathrm{Du}^{1}$, Jing Chen ${ }^{2}$, Jianxun $\mathrm{Cui}^{2}$, Xiaoning Wang ${ }^{1}$ and Xiquan Zhang ${ }^{2}$ \\ ${ }^{1}$ School of Bioscience and Bioengineering, South China University of Technology, Guangzhou, China. \\ ${ }^{2}$ College of Animal Science, South China Agricultural University, Guangzhou, China.
}

\begin{abstract}
Several quantitative trait loci (QTL) for important reproductive traits (ovulation rate) have been identified on the porcine chromosome 15 (SSC15). To assist in the selection of positional candidate swine genes for these QTL on SSC15, twenty-one genes had already been assigned to SSC15 in a previous study in our lab, by using the radiation hybrid panel IMpRH. Further polymorphism studies were carried out on these positional candidate genes with four breeds of pigs (Duroc, Erhualian, Dahuabai and Landrace) harboring significant differences in reproduction traits. A total of nineteen polymorphisms were found in 21 genes. Among these, seven in six genes were used for association studies, whereby NRP2 polymorphism was found to be significantly $(p<0.05)$ associated with litter-size traits. NRP2 might be a candidate gene for pig-litter size based on its chromosome location (Du et al., 2006), significant association with litter-size traits and relationships with Sema and the VEGF super families.
\end{abstract}

Key words: porcine, reproductive traits, NRP2, candidate gene.

Received: January 14, 2008; Accepted: July 23, 2008.

\section{Introduction}

More than 1800 quantitative trait loci (QTL) had already been mapped on the entire pig genome until June $3^{\text {rd }}$, 2008 , based on statistics available in the Pig QTL Database. The next step would be to identify candidate genes for these traits by developing a detailed comparative map and a SNP map that would both constitute an effective method for assisting in the selection of the underlying genes responsible for the mapped QTL. For example, a QTL affecting meat quality in chromosome $2 \mathrm{p}$ has already been well described (Andersson-Eklund et al. 1998; Knott et al. 1998; de Koning et al. 1999), these methods being essential in the identification of regulatory mutation in the causal gene IGF-2 (Jeon et al. 1999; Nezer et al. 1999; de Koning et al. 2000; Nezer et al. 2003; Van Laere et al. 2003).

Single nucleotide polymorphisms (SNP) are far more abundant, with the occurrence of about one SNP per $1000 \mathrm{bp}$ in human beings (Wang et al. 1998) and one SNP per $200 \mathrm{bp}$ in chickens (International Chicken Polymorphism Map Consortium, 2004), and are more amenable to assessment on using high-throughput genotyping technologies. Furthermore, SNP are extremely stable, occurring at a rate of only one mutation in $2 \times 10^{8}$ nucleotides in humans (Sachidanandam et al. 2001). A straightforward strategy for the identification of SNP is locus-specific amplification (LSA) and comparative re-sequencing from multiple indi-

Send correspondence to Xiquan Zhang. College of Animal Science, South China Agricultural University, Wushan Street, Guangzhou 510642, China. E-mail: xqzhang@ scau.edu.cn. viduals (Rieder et al. 1998). In addition, knowledge of local linkage disequilibrium (LD) and common haplotype patterns in disease association and positional cloning studies is becoming increasingly widespread since it has become clear (Rioux et al. 2001; Van Eerdewegh et al. 2002; Geesaman et al. 2003; Stoll et al. 2004) that intelligent use of this information has the potential of making them much more comprehensive and efficient. LD plays a fundamental role in the fine mapping of QTL and in proposed genome-wide association studies (Nezer et al. 2003).

QTLs for the ovulation rate (OR) were detected in the porcine chromosome 15q21-q26 (Rathje et al. 1997; Rohrer et al. 1999). The identified region spans over $60 \mathrm{cM}$, which corresponds to chromosomal fragments containing hundreds of genes. In a previous study in our lab, twenty-one genes were assigned to SSC15 by using the radiation hybrid panel IMpRH (Du et al, 2006). The goal of the present study was to screen SNP in these genes and investigate their association with litter size for identifying candidate genes in this QTL region. Seven polymorphisms were chosen for investigating their effects on litter size by using animals (unrelated individuals) which had already been recorded for litter-size traits.

\section{Materials and Methods}

\section{Pig populations}

Ear samples from 237 domestic pigs from the four breeds, Duroc, Erhualian, Dahuabai and Landrace, num- 
bering 38, 58, 61 and 80 individuals, respectively, were randomly collected from the Guangdong Wenshi Foodstuff Co. Ltd. (Guangdong, China), Guangdong Changjiang Foodstuff Company Ltd. (Guangdong, China) and Guangdong Banling Pig Farm (Guangdong, China). One hundred and fifty eight individuals were recorded as originating 4 or more than 4 litters. A fertility index was calculated individually by litter size, prenatal survival and litter-weight for all the litters of the 158 animals and assigned to three parameters: litter size (LS), prenatal survival (PS), litter-weight (LW).

\section{Genomic DNA pool preparation}

Porcine genomic DNA was extracted from ear samples using the Nucleon kit (TaKaRa, Japan). DNA concentrations were determined by O.D. measurements, using a Biophotometer (Eppendorf, Germany). All samples were diluted to a concentration of $20 \mathrm{ng} / \mu \mathrm{L}$. The breed DNA pool was constructed by mixing 30 samples from each breed at equal volume, whereby four breed DNA pools (Duroc, Erhualian, Dahuabai and Landrace) were obtained.

\section{PCR and sequencing}

The 21 primer pairs (Table 1) were also used to amplify genomic DNA fragments with the four breed DNA pools described above. Direct sequencing of these PCR products was performed using an ABI 377 automatic se- quencer (Applied Biosystems, Foster City, Calif., USA) following standard protocols. The sequence for each single gene was subjected to a BLAST search to confirm both its origin and ortholog status.

PCR reactions were performed in a final volume of $25 \mu \mathrm{L}$ containing $50 \mathrm{ng}$ of porcine genomic DNA, $0.4 \mu \mathrm{M}$ of each primer, $200 \mu \mathrm{M}$ of each dNTPs, $1.5 \mathrm{mM} \mathrm{MgCl}_{2}, 1 \mathrm{x}$ Taq buffer, and $0.7 \mathrm{U}$ of Taq polymerase (TaKaRa, Tokyo, Japan.). PCR conditions were as follows: $94{ }^{\circ} \mathrm{C}$ for $5 \mathrm{~min}$ and 35 cycles of $30 \mathrm{~s}$ at $94^{\circ} \mathrm{C}, 30 \mathrm{~s}$ at annealing temperature (Table 1) and $30 \mathrm{~s}$ at $72^{\circ} \mathrm{C}$, followed by a final 5 min extension at $72{ }^{\circ} \mathrm{C}$. PCR products were then examined by electrophoresis on a $2 \%$ agarose gel stained with ethidium bromide and then photographed.

\section{Polymorphism identification and selection}

Sequencing gel images obtained from previous experiments were analyzed using Sequencing Analysis software (Applied Biosystems, Foster City, Calif., USA) for lane tracking and trace file extraction. Subsequently, all trace files were analyzed using the Pregap4 program of the Staden software package (Bonfield and Staden 1996; http://www.mrc-lmb.cam.ac.uk/pubseq). All nucleotide positions at which disagreement occurred were tagged as putative polymorphism positions. Sequences were submitted to the GenBank. Polymorphisms identified in the se-

Table 1 - Information for PCR amplification of the genes genotyped on the IMpRH panel.

\begin{tabular}{|c|c|c|c|c|}
\hline Gene name & Primers (forward/ reverse) & $\operatorname{Tm}\left({ }^{\circ} \mathrm{C}\right)$ & Porcine sequence Acc. $n$. & Length (bp) \\
\hline ACVR1 & TGGTGTCACATGGGTAATGG/GGCTGCATACTCCAACTGGT & 60 & AY805729 & 395 \\
\hline ARHE & GACCTTTATATTGTTGGCGC/ACTGCAACGAAAGTTCTGCT & 56.5 & AY805745 & 341 \\
\hline CED-6 & CCCAACATCCACTGTAGATC/TGCCATCTGTCTCATGAGTG & 58 & AY805705 & 324 \\
\hline CMYA3 & GCAATGCCCTCTTCAGATAC/CAGCAGTACAGAATGTCACC & 58.5 & AY805685 & 690 \\
\hline COL4A4 & CATACCTTGCCACTGGGTTG/АTCTCTTTGCCTTCCCCTGA & 60 & AY805733 & $305 / 303$ \\
\hline DPP4 & ATGGCAGGATTTGGGCAGTG/CAGGGCAAGCTGATGTGTTC & 61 & AY805665 & 420 \\
\hline EPHA4 & GTGGTATCGGTGGGTGATTG/TTCTGCCGTGTATCTGTTGC & 61 & AY805669 & $553 / 552$ \\
\hline FLJ11457 & AAGGCCCGTGCATGTTTAAG/CCCGGAAGTTTACTCAAGTC & 58.5 & AY805681 & 438 \\
\hline GAD1 & AGTCACTTTACCTTCAGCGG/GCAGATGCTATGCAAGTGTG & 58.5 & AY805689 & 664 \\
\hline HAT1 & TGTGGAAGATTATCGACGTG/CAGTGGTATTTCAGAAGCTC & 58.5 & AY805693 & 268 \\
\hline HES6 & AGAGGATGGCTTGCCGTGAA/ATGCAAGACATACAGGGAGC & 60 & AY805725 & 383 \\
\hline HSPE1 & GGCAGTACTGCAGGTCTTTC/CTGATCCAACAGCTACTACG & 58 & AY805709 & $748 / 747$ \\
\hline $\mathrm{KCNJ3}$ & TGGTCCCTATTTCAACTGCG/TGTTAGGCCAGAGATCTAGG & 61 & AY805673 & 394 \\
\hline KLF7 & TTCTCTCGACAGCTACACGG/TTCTTGTTTTCGGGGCATGC & 60 & AY805737 & 297 \\
\hline NFE2L2 & AGCCTTACTCTCCAAGTGAG/ACGTATACAGAAACTAGCCC & 58 & AY805713 & 349 \\
\hline NR4A2 & AGCTCCCAGAACTTCGTACG/GTCCCCTTACAATGTGGGTG & 58.5 & AY805701 & 554 \\
\hline NRP2 & CTCTGGCTGACAAGGAGAAG/CGTCAGATGTGATGTGGGTG & 60 & AY805721 & 275 \\
\hline ORC2L & GGAAGTTTGAAGCTCTCCTA/CTGACATACGGAATAGCAGA & 56.5 & AY805717 & $476 / 472$ \\
\hline SH3BP4 & CATGGACCAGGACGACTATG/GCATCTGCCCCTATGAAGTG & 58.5 & AY805697 & $418 / 417$ \\
\hline SP3 & AAACCCATATGTCTGCCAGG/AGGTGAACTGCTGCAGTTAC & 62 & AY805677 & 431 \\
\hline TRIP12 & GAAGCTGTTGATGGCGGCAA/GGGGCCATGAATGAATATGA & 60 & AY805741 & 220 \\
\hline
\end{tabular}


quences are represented by the IUB ambiguity codes reflecting alleles found in the DNA pools.

In addition, the preliminary allele distribution of each polymorphism in each breed could be estimated based on peak heights at the polymorphic site in trace files (Cui et al. 2005). The effect of these markers on reproduction traits could be deduced to some extent, due to the diverse allelic distribution in different breeds. According to this principle, the seven polymorphisms identified in six genes (DPP4, SH3BP4, ORC2L, NRP2, COL4A4 and TRTP12) were selected and genotyped by the PCR-RFLP method, their effects on litter size being investigated by using unrelated individuals wherein the trait of litter size had already been recorded.

\section{Genotyping, haplotype construction and allelic frequency}

A total of 237 individuals from the four breeds Duroc, Erhualian, Dahuabai and Landrace, numbering 38, 58, 61 and 80 individuals, respectively, were genotyped by the PCR-RFLP method at the seven polymorphism sites, selected as above. Fragments of DPP4, SH3BP4, ORC2L, NRP2, and TRTP12 were digested by the CfrI, XapI, BseMI, Eco105I and Bsh1236I endonucleases, respectively, and the COL4A4 fragment by the TasI and NdeI endonucleases, to be then electrophoresed on 3\% agarose gel for genotyping. The allelic frequencies of the seven polymorphisms were calculated in all the populations.

Haplotypes were constructed with two SNP for COL4A4 in all experimental animals, through applying the PHASE programme (Stephens et al. 2001), with the reconstruction of haplotypes from population data as the main function. The minimum haplotype frequency was set at $2 \%$.

\section{Linkage disequilibrium analyses}

In this study, LD analyses were performed using HAPLOVIEW software (Barrett et al. 2005) in a population of 237 individuals, and LD measured with a parameter of $\mathrm{r}^{2}$ (Ardlie et al. 2002).

\section{Marker-trait association analysis}

The association of single polymorphism or haplotype with litter size was analyzed by means of the GLM procedure of SAS 8.0 (Statistical Analysis Systems Institute Inc., Cary, NC, USA). The model included parity, genotype (or haplotype), farm and breed as fixed effects for all the 158 animals. In addition, an association study was also carried out for each breed. Values were considered significant at $\mathrm{p}<0.05$ and presented as least square means $(\mathrm{LSM}) \pm$ standard error means (SEM).

\section{Results}

\section{Gene sequencing}

Direct sequencing of the 21 gene PCR products in both directions yielded reliable and readable sequences for pooled DNA samples from Duroc, Erhualian, Dahuabai and Landrace pigs.

\section{Polymorphism identification}

Direct sequencing of the 21 gene PCR products in both directions yielded 168 readings, all of which being assembled in 21 distinct contigs for the four pooled DNA samples. Contigs varied in length between 220 and 748 bp, with an average of $429 \mathrm{bp}$, and a total length of $8943 \mathrm{bp}$. The assembled sequences were submitted to GenBank, and accepted with the uninterrupted accession numbers from AY805665 to AY805748 (Table 1). At least one polymorphism was identified in 11 genes (COL4A4, DPP4, EPHA4, HES6, HSPE1, KCNJ3, NRP2, ORC2L, SH3BP4, SP3 and TRIP12) among the 21 genes analyzed. We identified 19 polymorphic positions in the total contig length of 8 $943 \mathrm{bp}$, corresponding to an overall average of one polymorphism per $470 \mathrm{bp}$. Most of these, 14 out of the 19, are located in the SSC15 q23-q25 region. Detailed information on each polymorphism is available in the submitted sequences.

\section{Genotypes, haplotypes and their frequencies}

Three haplotypes were found at each site of six genes (DPP4, SH3BP4, ORC2L, NRP2, COL4A4 and TRTP12). Large breed differences were observed in the allelic frequencies of 6 SNPs and 4-bp indel (Table 2). The most significant differences were found between the Duroc and Erhualian breeds at the T-SH3BP4-G, T-NRP2-C and CCOL4A4-2-T sites.

Haplotypes constructed based on two SNPs of the COL4A4 gene and their frequencies in four populations, are shown in Table 3. Four haplotypes were identified in 237 individuals, in which the three most abundant, designated $\mathrm{H} 1$ (C T), H2 (C A) and H3 (T A), accounted for 98\% of frequency. Haplotype H4 (T T) seems to correspond to a recombination between $\mathrm{H} 1$ and $\mathrm{H} 3$ and is present only in Duroc pigs. Their frequencies are significantly different among the four breeds.

\section{LD and marker-trait association}

The $r^{2}$ value was estimated for each of two polymorphic sites, the highest $r^{2}$ value (0.59) being obtained between the ORC2L and NRP2 polymorphic sites and the two loci forming a haplotype block.

The effect of single polymorphism or haplotype on reproduction traits in pigs was estimated simultaneously for the parameters of LS, PS and LW. We found that NRP2 genotypes had a significant effect on litter-size traits (type III $F=5.18, p=0.0059$ for LS; type III $F=5.70, p=0.0035$ for PS; type III $\mathrm{F}=9.17, \mathrm{p}=0.0001$ for $\mathrm{LW}$ ), whereas all the other genotypes at any other polymorphism site had no effect whatsoever on reproduction traits. The significant effect of NRP2 genotypes can also be inferred by association analysis which was carried out for Dahubai and Landrace 
Table 2 - Allele frequencies of the 7 polymorphic sites in 4 pig populations and Pearson's $\chi^{2}$ value.

\begin{tabular}{|c|c|c|c|c|c|c|c|c|c|c|c|c|c|c|}
\hline \multirow[t]{2}{*}{ Breeds (n. pig) ${ }^{\mathrm{a}}$} & \multicolumn{2}{|c|}{ DPP4-1 } & \multicolumn{2}{|c|}{ SH3BP4 } & \multicolumn{2}{|c|}{ ORC2L } & \multicolumn{2}{|c|}{ NRP2 } & \multicolumn{2}{|c|}{ COL4A4-2 } & \multicolumn{2}{|c|}{ COL4A4-3 } & \multicolumn{2}{|c|}{ TRTP12 } \\
\hline & $\mathrm{C}$ & $\mathrm{T}$ & $\mathrm{T}$ & G & - & $\begin{array}{c}\text { GTA } \\
\text { C }\end{array}$ & $\mathrm{T}$ & $\mathrm{C}$ & $\mathrm{C}$ & $\mathrm{T}$ & $\mathrm{T}$ & A & G & A \\
\hline Duroc (38) & 0 & 1.00 & 0 & 1 & 0 & 1.00 & 0 & 1.00 & 0.46 & 0.54 & 0.51 & 0.49 & 0.46 & 0.54 \\
\hline Erhualian (58) & 0.29 & 0.71 & 1.00 & 0 & 0.35 & 0.65 & 0.70 & 0.30 & 1.00 & 0 & 0.21 & 0.79 & 0.59 & 0.41 \\
\hline Dahuabai (61) & 0.52 & 0.48 & 0.96 & 0.04 & 0.70 & 0.30 & 0.66 & 0.34 & 0.93 & 0.07 & 0.53 & 0.47 & 0.28 & 0.72 \\
\hline Landrace (80) & 0.04 & 0.96 & 0.14 & 0.86 & 0 & 1.00 & 0.04 & 0.96 & 0.76 & 0.24 & 0.31 & 0.69 & 0.13 & 0.87 \\
\hline$\chi_{6}^{2}{ }^{b}$ & \multicolumn{2}{|c|}{105.77} & \multicolumn{2}{|c|}{234.41} & \multicolumn{2}{|c|}{186.33} & \multicolumn{2}{|c|}{203.80} & \multicolumn{2}{|c|}{103.35} & \multicolumn{2}{|c|}{57.80} & \multicolumn{2}{|c|}{66.04} \\
\hline Acc. $n^{c}$ & \multicolumn{2}{|c|}{ AY805665 } & \multicolumn{2}{|c|}{ AY805697 } & \multicolumn{2}{|c|}{ AY805717 } & \multicolumn{2}{|c|}{ AY805721 } & \multicolumn{2}{|c|}{ AY805733 } & \multicolumn{2}{|c|}{ AY805733 } & \multicolumn{2}{|c|}{ AY805741 } \\
\hline Variation position & \multicolumn{2}{|c|}{ Pos 296} & \multicolumn{2}{|c|}{ Pos 242} & \multicolumn{2}{|c|}{ Pos 187} & \multicolumn{2}{|c|}{ Pos 62} & \multicolumn{2}{|c|}{ Pos 147} & \multicolumn{2}{|c|}{ Pos 188} & \multicolumn{2}{|c|}{ Pos 69} \\
\hline
\end{tabular}

${ }^{\mathrm{a}}$ The number in brackets is the individual number investigated in each breed.

${ }^{\mathrm{b}} \chi_{6}^{2}>16.81, \mathrm{p}<0.01$.

${ }^{\mathrm{c}}$ Porcine sequence accession numbers.

Table 3 - Base constitutions of COL4A4 haplotypes and their frequencies.

\begin{tabular}{lccccccc}
\hline Haplotype & \multicolumn{2}{c}{ Sites } & & \multicolumn{4}{c}{ Frequencies } \\
\cline { 2 - 3 } \cline { 6 - 8 } & COL4A4-2 & COL4A4-3 & & Duroc(38) & Erhualian(58) & Dahuabai (61) & Landrace (80) \\
\hline h1 & $\mathrm{C}$ & $\mathrm{T}$ & & 0.43 & 0.79 & 0.53 & 0.31 \\
$\mathrm{~h} 2$ & $\mathrm{C}$ & $\mathrm{A}$ & & 0.03 & 0.21 & 0.40 & 0.45 \\
$\mathrm{~h} 3$ & $\mathrm{~T}$ & $\mathrm{~A}$ & & 0.46 & 0 & 0.07 & 0.24 \\
h4 & $\mathrm{T}$ & $\mathrm{T}$ & & 0.08 & 0 & 0 & 0 \\
\hline
\end{tabular}

${ }^{a}$ The number in brackets is the individual number investigated in each breed.

individuals, with the SAS GLM procedure including parity and genotype (or haplotype) as fixed effects (Table 4).

\section{Discussion}

In our previous study (Du et al., 2006), all the genes except ARHE, SH3BP4 and HES6 had been mapped within the QTL regions at 53-101 cM, and 79.3-102.5 cM characterized for the ovulation rate (Pig QTL Database, QTL on Pig Chromosome 15). Therein, KLF7, NRP2 and ORC2L were located very close to the QTL center position $(79 \mathrm{cM})$ (Rohrer et al. 1999), as the adjacent microsatellites SW1316, SWR1002 and SW2083 were mapped at $73.1 \mathrm{cM}, 76 \mathrm{cM}$ and $81.1 \mathrm{cM}$, respectively, on the MARC genetic map, all available at http://www.animalgenome.org/maps/marc.html. Similarly, EPHA4, COL4A4 and TRIP12 were located near to the QTL center position (88.5 cM) (Rathje et al. 1997), deduced from the position of SW936, SW906 and SW2608 mapped at $88.5 \mathrm{cM}, 89.3 \mathrm{cM}$ and $95 \mathrm{cM}$ respectively on the MARC genetic map. Therefore, these six genes are the most possible positional candidate genes among the 21 genes analysed.

Erhualian is one of the Taihu breeds with the highest fertility, producing around 16 piglets all told and 14 live piglets on an average per litter. Dahuabai is a native Chinese breed which produces about 14 piglets overall and 13 live piglets on an average per litter. Landrace and Duroc are breeds with a rapid growth rate, but producing far fewer piglets per litter than native Chinese breeds do. The four breeds were investigated to screen for potential polymorphisms related to reproductive traits in SSC15 based on DNA pooling and sequencing due to their very different litter sizes. Seven polymorphisms in the six genes DPP4, SH3BP4, ORC2L, NRP2, COL4A4 and TRTP12 were selected and genotyped for 237 individuals for further LD and marker-trait association studies, based on approximate allele distribution in the four breeds. Allelic frequency studies revealed that the frequencies of T-SH3BP4, T-NRP2 and C-COL4A4-2 varied significantly among the four breeds, the most significant differences being found especially between the Duroc and Erhualian breeds at the three sites. However, only the significant association of $\mathrm{T}$ NRP2-C with litter size traits (type III $\mathrm{F}=5.18, \mathrm{p}=0.0059$ for LS; type III $\mathrm{F}=5.70, \mathrm{p}=0.0035$ for PS; type III $F=9.17, p=0.0001$ for $L W$ ) was observed when further association studies were carried out on each polymorphism (Table 4). The over dominance expressions of T-NRP2-C for the PS trait are also to be found in Table 4. The significant difference between TC and CC or TT for traits can also be observed in the Landrace and Dahuabai breeds, which can validate the results for all the animals to some extent. 
The association of NRP2 with litter-size traits is consistent with the QTL which was characterized for the ovulation rate (Rohrer et al. 1999), since the latter is a major factor for litter size. Neuropilin (NRP, previously referred to as A5) is a type I transmembrane protein which is widely distributed in vertebrate species such as Xenopus, chickens and mice (Fujisawa et al. 1995). The extracellular part of the neuropilin protein is composed of three unique domains, each of which is thought to be involved in molecular and/or cellular interactions (Kitsukawa et al. 1995). NRP2 is a member of the related neuropilin family.. It is a receptor for the secreted semaphorins Sema IV and Sema E, and acts selectively to mediate repulsive guidance events in discrete populations of neurons (Chen et al. 1997). It has also been found to be a receptor for the vascular endothelial growth factor (VEGF) forms VEGF-145 and VEGF-165 and for additional VEGF family-members, such as the placenta growth factor (PlGF-2) (Gluzman-Poltorak et al. 2000; Neufeld et al. 2002). VEGF induces endothelial cell proliferation, promotes cell migration and inhibits apoptosis. A recent study has revealed that NRP2 is probably related to lymphangiogenic growth (Lohela et al. 2003) and a deficiency in NRP2 suppresses VEGF-induced retinal neovascularization (Shen et al. 2004). In conclusion, NRP2 can be considered as a candidate gene for litter-size traits based on its chromosome location, significant association with litter-size traits and relationships with the Sema and VEGF super families.

\section{Acknowledgments}

This work was funded by projects under the Major State Basic Research Development Program, China, project no. 2006CB102100

\section{References}

Andersson-Eklund L, Marklund L, Lundstrom K, Haley CS, Andersson K, Hansson I, Moller M and Andersson L (1998) Mapping quantitative trait loci for carcass and meat quality traits in a wild boar x Large White intercross. J Anim Sci 76:694-700.

Ardlie KG, Kruglyak L and Seielstad M (2002) Patterns of linkage disequilibrium in the human genome. Nat Rev Genet 3:299-309.

Barrett JC, Fry B, Maller J and Daly MJ (2005) Haploview: Analysis and visualization of LD and haplotype maps. Bioinformatics 21:263-265.

Chen H, Chedotal A, He Z, Goodman CS and Tessier-Lavigne M (1997) Neuropilin-2, a novel member of the neuropilin family, is a high affinity receptor for the semaphorins Sema E and Sema IV but not Sema III. Neuron 19:547-559.

Cui JX, Du HL and Zhang XQ (2005) Rapidly screening SNP and estimating allelic frequencies by DNA pooling and sequencing. Acta Genet Sin 32:372-377.

de Koning DJ, Janss LL, Rattink AP, van Oers PA, de Vries BJ, Groenen MA, vander Poel JJ, de Groot PN, Brascamp EW and van Arendonk (1999) Detection of quantitative trait loci 
for backfat thickness and intramuscular fat content in pigs (Sus scrofa). Genetics 152:1679-1690.

de Koning DJ, Rattink AP, Harlizius B, van Arendonk JA, Brascamp EW and Groenen MA (2000) Genome-wide scan for body composition in pigs reveals the important role of imprinting. Proc Natl Acad Sci USA 97:7947-7950.

Du HL, Chen J, Cui JX, Zhang YS, Yerle M, Milan D and Zhang XQ (2006) Radiation hybrid mapping and sequence analysis of 21 genes on porcine chromosome 15. Anim Genet 37:181-183.

Fujisawa H, Takagi S and Hirata T (1995) Growth-associated expression of a membrane protein, neuropilin, in Xenopus optic nerve fibers. Dev Neurosci 17:343-349.

Geesaman BJ, Benson E, Brewster SJ, Kunkel LM, Blanche H, Thomas G, Perls TT, Daly MJ and Puca AA (2003) Haplotype-based identification of a microsomal transfer protein marker associated with the human lifespan. Proc Natl Acad Sci USA 100:14115-14120.

Gluzman-Poltorak Z, Cohen T, Herzog Y and Neufeld G (2000) Neuropilin-2 is a receptor for the vascular endothelial growth factor (VEGF) forms VEGF-145 and VEGF-165. J Biol Chem 275:18040-18045.

International Chicken Polymorphism Map Consortium (2004) A genetic variation map for chicken with 2.8 million single-nucleotide polymorphisms. Nature 432:717-722.

Jeon JT, Carlborg O, Tornsten A, Giuffra E, Amarger V, Chardon $\mathrm{P}$, Andersson-Eklund L, Andersson K, Hansson I, Lundstrom K et al. (1999) A paternally expressed QTL affecting skeletal and cardiac muscle mass in pigs maps to the IGF2 locus. Nat Genet 21:157-158.

Kitsukawa T, Shimono A, Kawakami A, Kondoh H and Fujisawa $H$ (1995) Overexpression of a membrane protein, neuropilin, in chimeric mice causes anomalies in the cardiovascular system, nervous system and limbs. Development 121:4309-4318.

Knott SA, Marklund L, Haley CS, Andersson K, Davies W, Ellegren H, Fredholm M, Hansson I, Hoyheim B, Lundstrom K et al. (1998) Multiple marker mapping of quantitative trait loci in a cross between outbred wild boar and large white pigs. Genetics 149:1069-1080.

Lohela M, Saaristo A, Veikkola T and Alitalo K (2003) Lymphangiogenic growth factors, receptors and therapies. Thromb Haemost 90:167-184.

Neufeld G, Kessler O and Herzog Y (2002) The interaction of Neuropilin-1 and Neuropilin-2 with tyrosine-kinase receptors for VEGF. Adv Exp Med Biol 515:81-90.

Nezer C, Collette C, Moreau L, Brouwers B, Kim JJ, Giuffra E, Buys N, Andersson L and Georges M (2003) Haplotype sharing refines the location of an imprinted quantitative trait locus with major effect on muscle mass to a $250-\mathrm{kb}$ chromosome segment containing the porcine IGF2 gene. Genetics 165:277-285.

Nezer C, Moreau L, Brouwers B, Coppieters W, Detilleux J, Hanset R, Karim L, Kvasz A, Leroy P and Georges M (1999) An imprinted QTL with major effect on muscle mass and fat deposition maps to the IGF2 locus in pigs. Nat Genet 21:155-156.
Rathje TA, Rohrer GA and Johnson RK (1997) Evidence for quantitative trait loci affecting ovulation rate in pigs. J Anim Sci 75:1486-1494.

Rieder MJ, Taylor SL, Tobe VO and Nickerson DA (1998) Automating the identification of DNA variations using quality-based fluorescence re-sequencing: Analysis of the human mitochondrial genome. Nucleic Acids Res 26:967-973.

Rioux JD, Daly MJ, Silverberg MS, Lindblad K, Steinhart H, Cohen Z, Delmonte T, Kocher K, Miller K, Guschwan S et al. (2001) Genetic variation in the $5 \mathrm{q} 31$ cytokine gene cluster confers susceptibility to Crohn disease. Nat Genet 29:223228.

Rohrer GA, Ford JJ, Wise TH, Vallet JL and Christenson RK (1999) Identification of quantitative trait loci affecting female reproductive traits in a multigeneration MeishanWhite composite swine population. J Anim Sci 77:13851391.

Sachidanandam R, Weissman D, Schmidt SC, Kakol JM, Stein LD, Marth G, Sherry S, Mullikin JC, Mortimore BJ, Willey DL et al. (2001) A map of human genome sequence variation containing 1.42 million single nucleotide polymorphisms. Nature 409:928-933.

Shen J, Samul R, Zimmer J, Liu H, Liang X, Hackett S and Campochiaro PA (2004) Deficiency of Neuropilin 2 suppresses VEGF-induced retinal neovascularization. Mol Med 10:12-18.

Stephens M, Smith N and Donnelly P (2001) A new statistical method for haplotype reconstruction from population data. Am J Hum Genet 68:978-989.

Stoll M, Corneliussen B, Costello CM, Waetzig GH, Mellgard B, Kroch WA, Rosenstiel P, Albrecht M, Croucher PJ, Seegert D et al. (2004) Genetic variation in DLG5 is associated with inflammatory bowel disease. Nat Genet 36:476-480.

Van Eerdewegh P, Little RD, Dupuis J, Del Mastro RG, Falls K, Simon J, Jorrey D, Pandit S, McKenny J, Braunschweiger K et al. (2002) Association of the ADAM33 gene with asthma and bronchial hyper-responsiveness. Nature 418:426-430.

Van Laere AS, Nguyen M, Braunschweig M, Nezer C, Collette C, Moreau L, Archibald AL, Haley CS, Buys N, Tally M et al. (2003) A regulatory mutation in IGF2 causes a major QTL effect on muscle growth in the pig. Nature 425:832-836.

Wang DG, Fan JB, Siao CJ, Berno A, Young P, Sapolsky R, Ghandour G, Perkins N, Winchester E, Spencer J et al. (1998) Large-scale identification, mapping, and genotyping of single-nucleotide polymorphisms in the human genome. Science 280:1077-1082.

\section{Internet Resources}

Pig QTL Database, http://www.animalgenome.org/cgi-bin/QTLdb/SS/summary (June 3, 2008).

Pig QTL Database, QTL on Pig Chromosome 15, http:/www.animalgenome.org/cgi-bin/QTLdb/SS/draw_ch romap?chromos $=15$ (June 3,2008$)$.

\section{Associate Editor: Pedro Franklin Barbosa}

License information: This is an open-access article distributed under the terms of the Creative Commons Attribution License, which permits unrestricted use, distribution, and reproduction in any medium, provided the original work is properly cited. 